\title{
On the Thermal Stratification of Sea Water and its Importance for the Algal Plankton.
}

\author{
By \\ W. R. G. Atkins, Sc.D., \\ Head of the Department of General Physiology at the Plymouth Laboratory.
}

With Three Figures in the Text.

IN a previous paper (1924) the writer considered the factors which bring about the mixing of surface water, warmed by the sun, with the cooler water below. Observations were cited to show that in the English Channel, between May and September, a warm surface layer may exist, which differs from the deeper water in being more alkaline and poorer in phosphates ; both these differences are due to the activity of the phytoplankton. The reduction in phosphate proceeds in the upper wellilluminated layer till none is left. No further increase in phytoplankton is then possible till phosphate is set free by decomposition or supplied by mixing with the deeper water. The phenomena of thermal stratification are consequently of great importance in the study of the phytoplankton.

Such stratification has been considered at length by Birge and Juday (1911) in their limnological studies. Birge (1910) designates the upper warm and the lower cold layers the "epilimnion " and "hypolimnion" respectively. These terms connoting very different biological habitats are undoubtedly useful, but from their derivation are not strictly applicable to sea water. It is suggested that the terms "epithalassa " and "hypothalassa" should be used to denote these layers in sea water, the region between them being denoted by the well-established term, thermocline, introduced by Birge in 1897.

The epithalassa usually persists throughout the summer months; though the rough seas of June, 1922, almost destroyed it, yet it became apparent again in August. Its stability is, in fact, surprising, but Birge (1910) has given reasons which render the persistence of the epilimnion intelligible. These apply equally to the epithalassa as shown by the figures which follow. 
The effectiveness of the resistance to mixing, due to increase of temperature, is not proportional to the temperature gradient simply, but depends also on the departure of this temperature from that of the maximum. density of the water.

The decrease in density as water is removed from the temperature of maximum density is not constant, but increases. Groll (1905) pointed out the bearing this has upon the origin of convection currents. Wind, however, appears to be the chief factor concerned in the mixing of warm

\begin{tabular}{rcrrrrr} 
& \multicolumn{5}{c}{ TABLE } & \\
$\mathrm{t}^{\circ}$ & \multicolumn{7}{c}{$\mathrm{D}^{\mathrm{t}}$} & $\Delta \times 10^{5}$ & $\begin{array}{c}\text { Relative } \\
\Delta \text { for } 2^{\circ} .\end{array}$ & $\begin{array}{c}\Delta \text { relative } \\
\text { to fresh } \\
\text { water. }\end{array}$ & $\begin{array}{c}\text { Ergs salt } \\
\text { water. }\end{array}$ & $\begin{array}{c}\text { Ergs fresh } \\
\text { water. }\end{array}$ \\
-2 & $1 \cdot 02845$ & 8 & $1 \cdot 00$ & $2 \cdot 50$ & 680 & - \\
0 & $1 \cdot 02837$ & 13 & $1 \cdot 62$ & $4 \cdot 05$ & 1083 & 833 \\
2 & $1 \cdot 02824$ & 19 & $2 \cdot 38$ & $5 \cdot 95$ & 1583 & 267 \\
4 & $1 \cdot 02805$ & 24 & $3 \cdot 00$ & $7 \cdot 50$ & 1997 & 267 \\
6 & $1 \cdot 02781$ & 28 & $3 \cdot 50$ & $8 \cdot 75$ & 2332 & 766 \\
8 & $1 \cdot 02753$ & 32 & $4 \cdot 00$ & $10 \cdot 0$ & 2665 & 1241 \\
10 & $1 \cdot 02720$ & 36 & $4 \cdot 50$ & $11 \cdot 25$ & 2998 & 1682 \\
12 & $1 \cdot 02684$ & 40 & $5 \cdot 00$ & $12 \cdot 5$ & 3332 & 2116 \\
14 & $1 \cdot 02644$ & 44 & $5 \cdot 50$ & $13 \cdot 75$ & 3665 & 2507 \\
16 & $1 \cdot 02600$ & 48 & $6 \cdot 00$ & $15 \cdot 0$ & 3997 & 2899 \\
18 & $1 \cdot 02552$ & 51 & $6 \cdot 39$ & $16 \cdot 0$ & 4248 & 3266 \\
20 & $1 \cdot 02501$ & 54 & $6 \cdot 75$ & $16 \cdot 9$ & 4498 & 3607 \\
22 & $1 \cdot 02447$ & 58 & $7 \cdot 25$ & $18 \cdot 1$ & 4831 & 4009 \\
24 & $1 \cdot 02389$ & 61 & $7 \cdot 62$ & $19 \cdot 05$ & 5046 & 4273 \\
26 & $1 \cdot 02328$ & 64 & $8 \cdot 00$ & $20 \cdot 0$ & 5331 & 4589 \\
28 & $1 \cdot 02264$ & 67 & $8 \cdot 37$ & $20 \cdot 95$ & 5581 & 4881 \\
30 & $1 \cdot 02197$ & - & - & - & - & -
\end{tabular}

surface water with cold bottom water. During the summer the density differences between the top and bottom are far greater than during the spring and autumn; it is this fact and not only the diminished force of the wind in summer that permits of the establishment and persistence of the epithalassa.

Birge has tabulated, for fresh water, temperatures from $0-30^{\circ} \mathrm{C}$., densities at $1^{\circ}$ intervals, the density differences for $1^{\circ}$ and the relative differences for $1^{\circ} \mathrm{C}$., taking that from $4^{\circ}$ to $3^{\circ}$ and from $4^{\circ}$ to $5^{\circ}$ as unity. He also tabulates, for temperatures from $0^{\circ}-30^{\circ}$, the number of ergs. 
work done against gravity in mixing a column of water of one square centimetre area, one metre high, whose upper and lower surfaces differ in temperature by $1^{\circ}$ the gradient being uniform. This may be calculated from the equation :-

$$
\mathrm{W}(\mathrm{ergs})=\frac{\mathrm{Ah}^{2}}{12}\left(\mathrm{D}_{2}-\mathrm{D}_{1}\right)
$$

where $A$ denotes the area and $h$ the height, $D_{1}$ and $D_{2}$ being respectively the densities of the lower and. upper strata of the column.

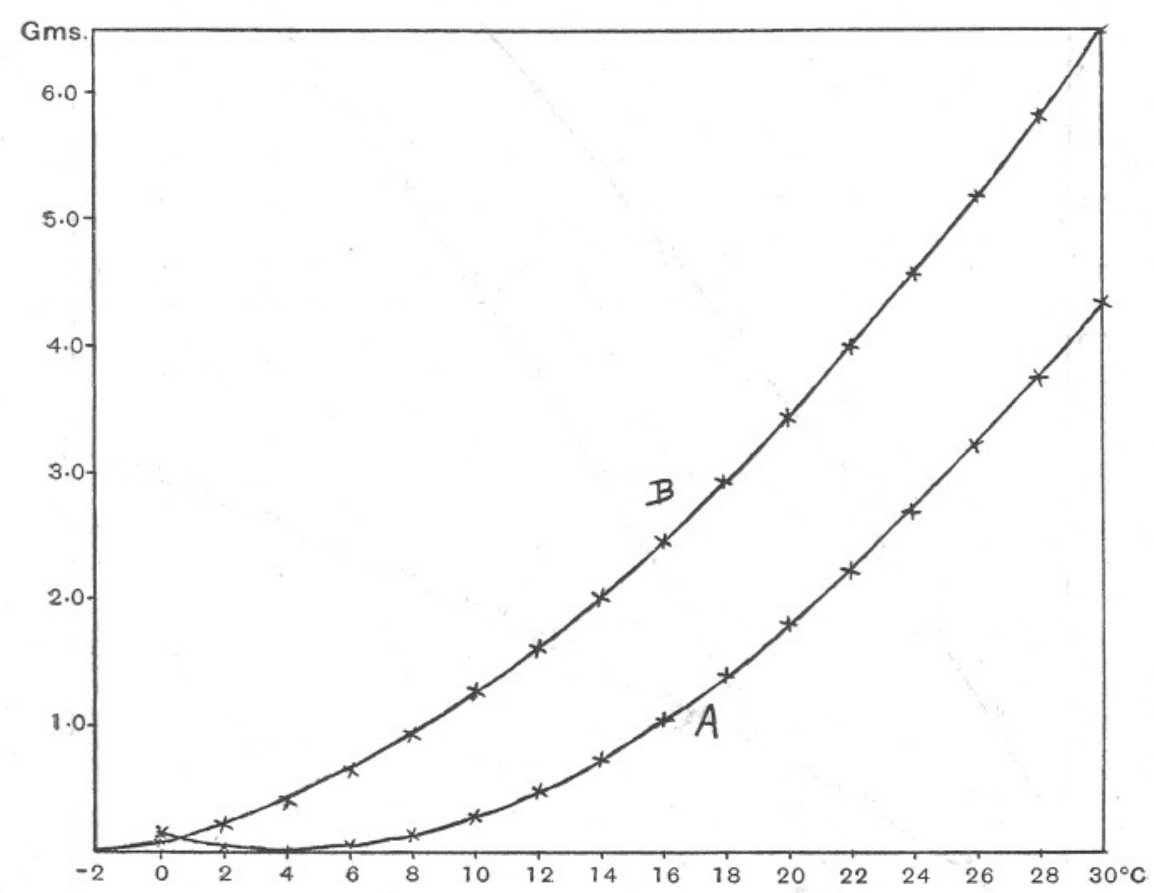

FIG. 1.-The curves represent changes in density due to rise of temperature. The ordinates show difference in weight, in grams, between a litre of water at temperature $t^{\circ}$ and $4^{\circ}$, curve $A$, and between $t^{\circ}$ and $-2^{\circ}$, curve $B$, which is for water of salinity $35 \cdot 3^{\circ} \%$. For example, in $\mathrm{B}, \mathrm{D}_{\frac{-2}{4}}=1 \cdot 02845$ and $\mathrm{D} \frac{14}{4}=1 \cdot 02644$, viz. 2.01 gms. less per litre, as may be read off on the curve.

The number of ergs is, therefore, 833 times the difference between the densities.

In order to apply these density changes to sea water calculations have been made of the density of sea water of $35 \cdot 3 \%$ salinity, such as is found in the west of the English Channel, at a series of temperatures from $-2^{\circ}$ to $30^{\circ}$. The freezing-point of such sea water 


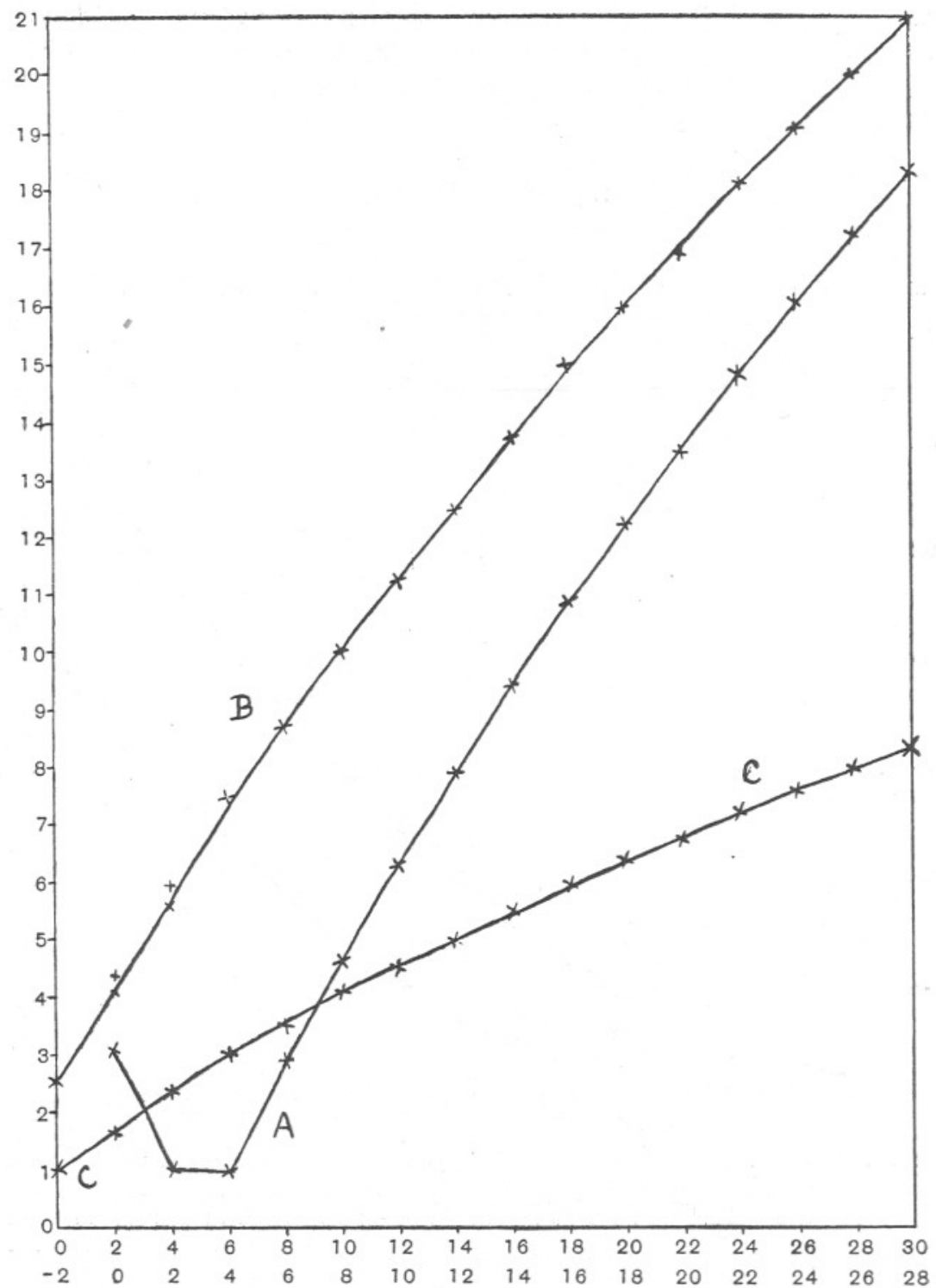

Frg. 2.-The ordinates indicate relative thermal resistance to mixing, and are in reality ratios of the change in density over the given ranges of $2^{\circ} \mathrm{C}$. relative to that of water from $4^{\circ}$ to $2^{\circ}$ or from $4^{\circ}$ to $6^{\circ}$ as unity, viz. the ratio of $\left(\mathrm{D} \frac{\mathrm{t}-2}{4}-\mathrm{D} \frac{\mathrm{t}}{4}\right)$ to $\left(\mathrm{D} \frac{4}{4}-\mathrm{D} \frac{2}{4}\right)=\left(\mathrm{D}_{\frac{4}{4}}-\mathrm{D} \frac{6}{4}\right)$. Curve $\mathrm{A}$ is for pure water, curve $\mathrm{B}$ for water of $\mathrm{S}=35 \cdot 3 \%$. Curve $\mathrm{C}$ is the ratio for $\left(\mathrm{D} \frac{\mathrm{t}-2}{4}-\mathrm{D} \frac{\mathrm{t}}{4}\right)$ relative to $\left(\mathrm{D} \frac{-2}{4}-\mathrm{D}_{\frac{0}{4}}\right)$ for the water of curve B. The abscissæ represent the temperatures of the upper and lower surfaces of a column of water of unit area and height, but for pure water the temperatures $4^{\circ}$ over $2^{\circ}$ and $2^{\circ}$ over $0^{\circ}$ should be inverted. 
differs by only a few hundredths of a degree from $-2^{\circ}$. For the calculations the formulæ and constants given in Knudsen's Hydrographical Tables were used.

In the table (see p. 694) are recorded the densities obtained as described, together with, under $\triangle$, their differences for intervals of $2^{\circ} \mathrm{C}$. The fourth column shows the values of $\Delta$ for $2^{\circ}$ intervals, relative to that

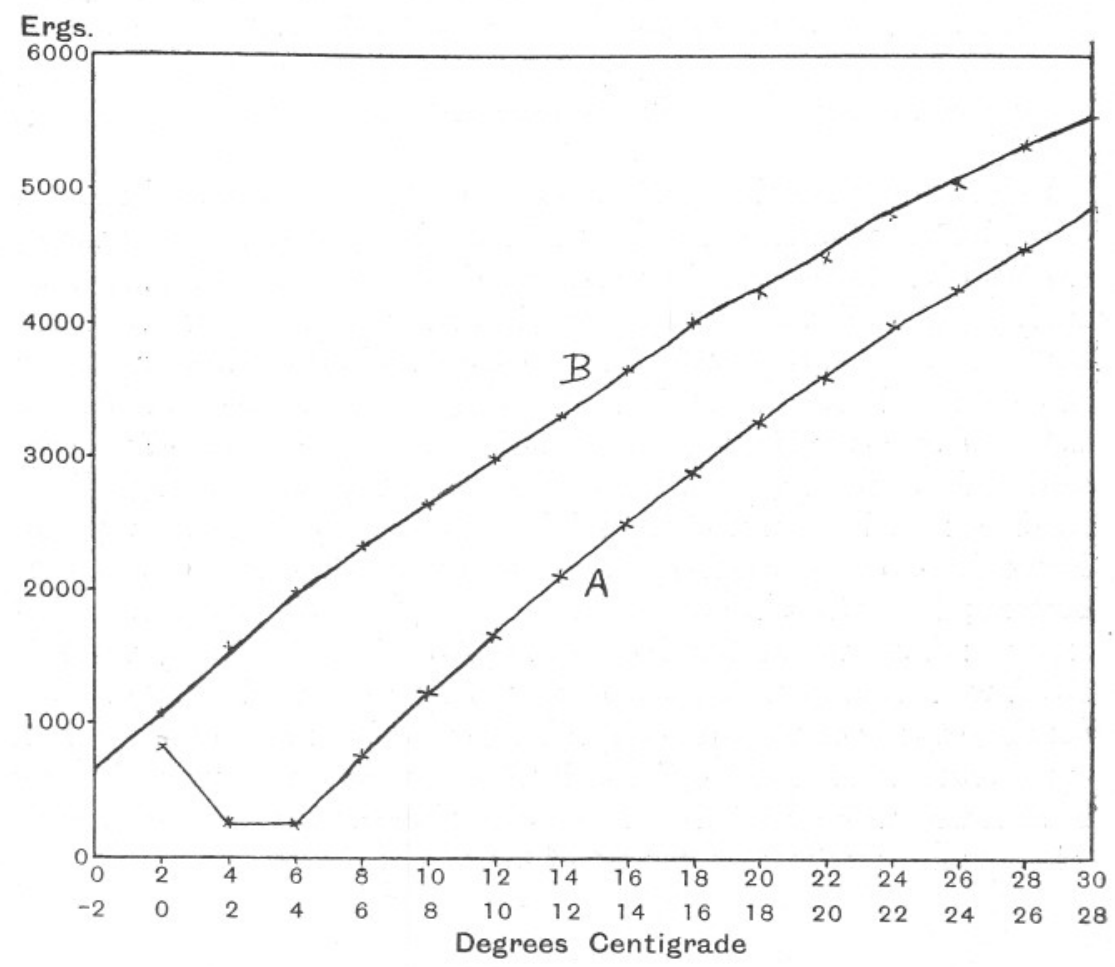

FIG. 3.-The ordinates show ergs of work done in mixing columns of water, one metre high and one square metre in area, whose upper and lower surfaces differ by $2^{\circ} \mathrm{C}$., the upper being the warmer. The abscissæ indicate the temperatures of the surfaces. Curve $\mathrm{A}$ is for pure water, modified from Birge. In it the temperature figures $2^{\circ}$ over $0^{\circ}$ and $4^{\circ}$ over $2^{\circ}$ should be read $0^{\circ}$ over $2^{\circ}$ and $2^{\circ}$ over $4^{\circ}$. Curve B is for water of $35 \cdot 3 \%$ salinity.

for $35.3^{\circ} \%$ salinity water between $-2^{\circ}$ and $0^{\circ}$. The fifth column records the values of $\triangle$ relative to that for pure water over the range $2^{\circ}$ to $4^{\circ}$ or $4^{\circ}$ to $6^{\circ}$ as unity. The sixth column sets forth the work done in mixing a water column as already described for sea water, but with $2^{\circ}$ temperature gradient. Also to obtain whole numbers the area taken was one square metre instead of one square centimetre. In the seventh column the corresponding values for fresh water have been quoted from Birge's 
paper, but as he calculated on a $1^{\circ}$ gradient the figures given here are the sums of his values taken in pairs. The value for $\triangle$ between $-2^{\circ}$ and $0^{\circ}$ is tabulated opposite $-2^{\circ}$ and similarly for the other values.

In Fig. 1 (p. 695) are plotted the temperature-density curves for both fresh and salt water, $35 \cdot 3 \%$ salinity. Fig. 2 (p. 696) shows the values of $\Delta$ relative to salt and fresh water, also values of $\Delta$ for fresh water modified from Birge's data, which are for $1^{\circ}$ intervals. In Fig. 3 (p. 697) the results of columns 6 and 7 are plotted, the temperatures of the tops and bottoms of the columns being abscissæ, as in Fig. 2, while the ordinates represent ergs of work required for mixing.

From Fig. 1 it may be seen that, on account of the complication introduced by the position of maximum density being at $4^{\circ}$ for fresh water, the rate of decrease in density per degree rise in temperature is far less for fresh than for salt water, but the rate becomes more nearly the same the higher the temperature. This is more clearly brought out by Fig. 2, from which it may be found that the mixing of, for example, a column of fresh water $10^{\circ}$ at its upper surface and $8^{\circ}$ at its lower is only about 47 per cent as difficult as mixing salt water of the same temperature and gradient. Again it may be seen that the mixing of a water column $12^{\circ}$ top, $10^{\circ}$ bottom, is $4 \cdot 5$ times as difficult as if the same column were $0^{\circ}$ top, $-2^{\circ}$ bottom; but if the temperatures were $16^{\circ}$ to $14^{\circ}$ respectively the resistance to mixing would have increased to $5 \cdot 5$ times. In Fig. 3 , which is based upon Fig. 2, the resistance to mixing is shown by plotting the number of ergs of work done in mixing one cubic metre of water with upper and lower surfaces differing by $2^{\circ}$ in favour of the upper. It may be seen that throughout the whole range plotted the mixing of fresh is effected more readily than is that of salt water.

\section{SUMMARY.}

1. A table has been drawn up showing the values of $D_{\frac{t}{4}}$ for water of $35 \cdot 3^{\circ}$ salinity from $t=-2^{\circ}$ to $t=30^{\circ}$. In it the values of $\triangle=\left(D^{t} \frac{-2}{4}-\right.$ $\left.\mathrm{D} \frac{\mathrm{t}}{4}\right)$ are shown as are also the values of $\triangle$ relative to $\left(\mathrm{D}_{\frac{-2}{4}}^{-\frac{2}{4}}-\mathrm{D}_{4}^{\frac{0}{4}}\right)$ as unity. In addition the values of $\triangle$ relative to $\left(D_{\frac{4}{4}}-D_{\frac{2}{4}}\right)=\left(D_{\frac{4}{4}}-D_{\frac{6}{4}}\right)$ for fresh water are tabulated. From the foregoing the number of ergs of work required to mix completely one cubic metre of water, with upper and lower surfaces having initial differences of $2^{\circ}$, have been calculated for sea water over the range $-2^{\circ}$ to $+30^{\circ}$. For comparison Birge's values for fresh water are quoted.

2. The rate of decrease in density with increase in temperature in- 
creases for both salt and fresh water, according as the actual temperature becomes further removed from the temperature of maximum density. Thus the relative value of $\triangle$ as defined above becomes $5 \cdot 0$ for water at $14^{\circ}$ to $12^{\circ}$ and 6.0 for $18^{\circ}$ to $16^{\circ}$, while $\triangle$ relative to fresh water for the latter temperatures has the value $15 \cdot 0$. Owing to the differences in the temperatures of maximum density more work is required to mix a cubic metre of salt water than of fresh water, for $16^{\circ}$ top to $14^{\circ}$ bottom the number of ergs required are, for example, 3997 and 2899 respectively.

3. It results that the mixing of the surface water with the deeper is less readily brought about in summer than in winter, both on account of the lesser amount of wind and the increased differences in density. The warm surface layer, or epithalassa, gets depleted of phosphate by the phytoplankton, and as long as it persists the phosphate in the deeper layers is not fully utilized. The stability or otherwise of the epithalassa is consequently of great importance.

\section{BIBLIOGRAPHY.}

Atkins, W. R. G. 1924. On the vertical mixing of sea water and its importance for the algal plankton. Journ. Marine Biol. Assoc., 13, 319-24.

Birge, E. A., and Juday, C. 1911. The inland lakes of Wisconsin. The dissolved gases of the water and their biological significance. Wisconsin Geol. and Nat. Hist. Survey, Bull No. 22, pp. 259.

Birge, E. A. 1910. I, An unregarded factor in lake temperatures. II, On the evidence for temperature seiches. Trans. Wisconsin Acad. of Sciences, Arts, and Letters, 16, 989-1004 and 1005-15.

Groll, M. 1905. Der Eschinensee. Jahresber. der Geog. Gesellschaft von Berlin, 19, 1-78. Cited from Birge. 